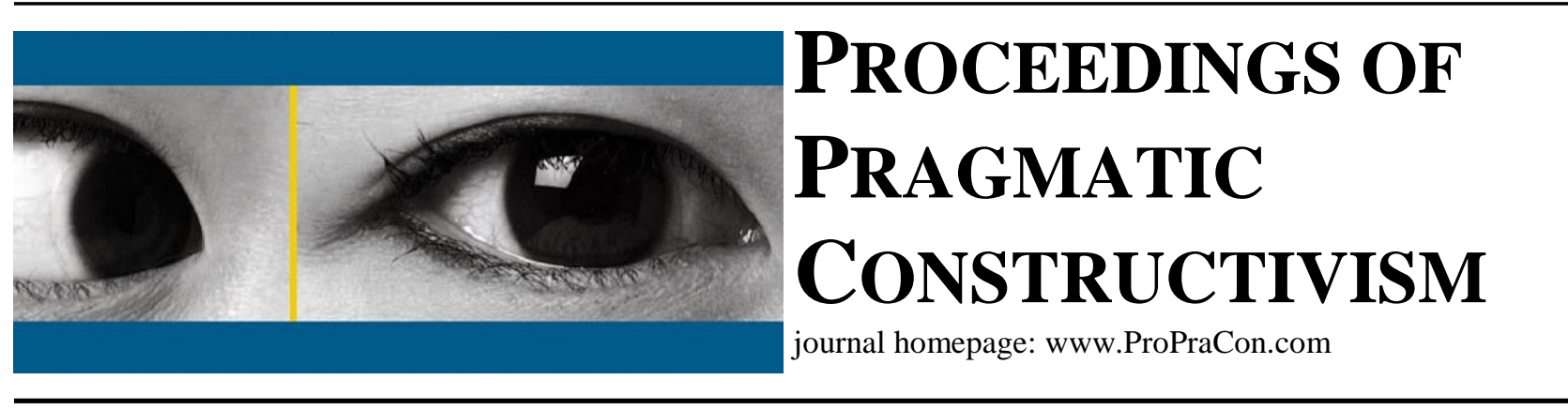

\title{
The Actor's Role in the Survival of non-financial Management and Reporting Practices: the case of IC reporting in Denmark and Italy
}

\author{
Stefan Schaper \\ Department of Management, Aarhus University, Denmark \\ E-mail: stefan.schaper@mgmt.au.dk \\ Marco Giuliani \\ Università Politecnica delle Marche, Italy \\ Maria Serena Chiucchi \\ Università Politecnica delle Marche, Italy
}

\begin{abstract}
According to Chaminade and Roberts (2003, p. 733) “(...) a dominant accounting perspective can lead to an excessive focus on measurement issues and little attention to management processes (of implementing Intellectual Capital in organizations)". By applying a pragmatic constructivist (PC) perspective, this paper intends to shed a different light on the demise of Intellectual Capital (IC) reporting by focusing on the role of the involved actors and how they construct reality. Therefore, it compares the government-driven IC Statement (ICS) in Denmark (Nielsen et al., 2017; Schaper 2016) with the case of voluntary consulting-driven adoption of IC reporting in Italy (Chiucchi and Giuliani, 2017; Giuliani and Chiucchi, 2018). The intent thereby is to derive policy- and managerial-relevant insights for the future installment of internal/external reporting frameworks as successfully lasting practices. Indeed, as suggested by Nørreklit et al. (2006), merely providing guidelines is not sufficient to solve the gap between theoretical knowledge and actual doing: it instead requires the integration of the four dimensions of PC to not end up in a realitydoing gap. The latter has arguably been the case of IC seen as a theory and practice respectively.
\end{abstract}

This article is sequentially articulated in a fashion similar to Seal and Ye (2014) and Jakobsen and Lueg (2014, p. 523):

It describes at first the implementation of ICS by comparing the peculiarities of two cases, i.e., the implementation in Denmark and Italy over the last 15 years. The paper builds on primary data from a sample of 60+ companies for the first and 15+ companies in the second case.

In the second phase, a PC methodological perspective is used to take a "more evaluative stance" (Seal and Ye, 2014, p. 478). This analysis re-constructs step-by-step whether the four PC dimensions were properly integrated in theory (measurement and reporting frameworks) and practice (practical deployment) and thus if changed organizational action occurred as the result of constructed reality and whether these changes were informed by reality or myth (Nørreklit et al., 2012; Seal and Ye, 2014).

Regarding the first phase, the aggregated findings deriving from the comparative exercise show the demise of the IC reporting as a practice in both cases. They also highlight the predominant role of some actors (project sponsor, project manager, the point of entry, etc.) in the creation of company-specific topoi. Indeed, the role of co-authorship 
(Jakobsen et al., 2011) of the actors emerged as relevant in the company-specific implementation of the ICS practice, i.e., the creation of reality from the theoretical framework (such as the ICS guideline).

Compared with the opposite results of Seal and Ye (2014), the non-survival of the ICS practice, i.e., its lack of organizational embeddedness, was in several cases connected to the missing (or not lasting) support from the top management and to the limited involvement of employees throughout the entire organization.

In the second phase, the following insights emerge from a step-by-step analysis of PC's dimensions:

Facts: It can be objectively argued that IC, intangibles, and knowledge resources are competitive resources relevant to manage and/or to disclose to the firm's stakeholders. Further, the lack of generally accepted concepts, methods, and tools has created situations of uncertainty and ambiguity and, consequently, a complex business environment (cf. Cinquini, 2013). In this context, specific local, national or international initiatives pushed forward by consultants or governments had the ambition to offer theoretical and practical solutions for managing, reporting and disclosing IC.

Possibilities: This dimension can be related to the opportunity companies had to join one of the mentioned initiatives, e.g., the Danish project or the project promoted by some Italian consultants. The choice among the possibilities was to a certain extent influenced by the actors' set of professional values. In particular, it is possible to identify a theoretical conflict between the values related to the creation of the accounting frameworks (Norreklit et al., 2010) and the ones related to the human resource, sustainability or public relations' spheres. On the other side, the constant search for alternative practices by the organizational actors (Seal and Ye, 2014) can be a further explanation of the demise of the ICS practice. In other words, it is possible that ICS has just evolved or some new possibilities (e.g., strategic reports or sustainability reports) were preferred.

Values: This perspective highlights the importance of the consultants'/ ICS project members' and internal sponsors' professional background, i.e., their system of values, in deciding, shaping or even hindering the implementation possibilities of the IC practice. Indeed, while in theory IC reporting is mainly conceived in the field of accounting, in practice it was often implemented in other departments such as the HR ones. This has implied a general mistrust among the accounting professionals in the organizations. Further, values are a source of motivation for actors (Norreklit et al., 2006) as they create objectives and are related to the actors' subjective preferences (Norreklit et al., 2010). The latter can represent the reason why the project sponsors played such an important role in ICS' survival as a practice. This suggests the need to create motivation that lasts and also spreads to other members of the organization if a practice is intended to last. However, the latter is an arguably difficult task since sets of professional values vary substantially within and especially between departments.

Communication: The isolation of the ICS practice and the lack of communication throughout the organization, as well as the limited interest from the external stakeholders, arguably hindered its survival/ legitimization over time. Although the integration or non-integration of the four dimensions was company specific in the short term, a clear convergence emerged in the medium and long-term. As a result, the attempt of unifying a practice with guidelines resulted in company-specific topoi, or in many cases non-topoi, based on how the four PC dimensions were or were not integrated. The lack of intra-professional communication (cf. Norreklit et al., 2010) resulted in the isolated existence of (a project sponsor's) individual reality (cf. Norreklit et al. 2006).

Finally, in the view of a diagnostic checklist of "what must be done for strategic and other plan to be effective" (Nørreklit et al., 2012, p. 506 as cited in Seal and Ye, 2014), the PC-based analysis here provides relevant insight for academics, professionals, standard setters and consultants in future endeavors of guidelines and their translation into effective practices. In doing so, the role of inclusive co-authorship of the implementing actors has to be taken into account. Tight guidelines or requirements, i.e., with limited possibilities (cf. Jakobsen and Lueg, 2014), instead reduce the space for co-creation and thereby limit people's engagement and consequently the survival of practices.

This study is limited by its ex-post reconstruction of the phenomenon from a PC perspective, thereby potentially leaving out of the analysis of other important elements. It has an extensive focus by analyzing a large number of cases, but in turn, it lacks the depth of analysis which case studies would instead provide. Besides the analysis in this paper, other reasons such as a limited value relevance, shifting management fads and fashions, etc. might have played a role as well.

This paper attempts to apply the PC framework to the study of a phenomenon including several companies as opposed to the commonly used single case study methodology. 


\section{References}

Chaminade C., and Roberts H. (2003) What it means is what it does: a comparative analysis of implementing intellectual capital in Norway and Spain, European Accounting Review, 12:4, 733-751

Chiucchi, M. S., \& Giuliani, M. (2017). Who's on Stage? The Roles of the Project Sponsor and of the Project Leader in IC Reporting. Electronic Journal of Knowledge Management, 15(3).

Cinquini, L., Tenucci, A., Campanale, C., \& Passetti, E. (2013). Understanding performance measurement in public organization under pragmatic constructivism, Proceedings of Pragmatic Constructivism, 3(1), 3-22.

Giuliani, M., \& Chiucchi, M. S. (2018). Guess who's coming to dinner: the case of IC reporting in Italy. Journal of Management and Governance, 1-31.

Jakobsen, M., \& Johansson, I. L. (2011). An Actor's Approach to Management: Conceptual Framework and Company Practises. DJøF Publishing.

Jakobsen, M., \& Lueg, R. (2014). Balanced scorecard and controllability at the level of middle managers - the case of unintended breaches. Journal of Accounting \& Organizational Change, 10(4), 516-539. https://doi.org/10.1108/JAOC-03-2013-0023

Nielsen, C., Roslender, R., \& Schaper, S. (2017). Explaining the demise of the intellectual capital statement in Denmark. Accounting, Auditing \& Accountability Journal, 30(1), 38-64.

Nørreklit, L., Nørreklit, H., \& Israelsen, P. (2006). The validity of management control topoi. Management Accounting Research, 17(1), 42-71. https://doi.org/10.1016/j.mar.2005.04.002

Nørreklit, H., Nørreklit, L., \& Mitchell, F. (2010). Towards a paradigmatic foundation for accounting practice. Accounting, Auditing \& Accountability Journal, 23(6), 733-758.

Nørreklit, H., Nørreklit, L., Mitchell, F. and Bjørnenak, T. (2012), “The rise of the balanced scorecard! Relevance regained?”, Journal of Accounting and Organizational Change, Vol. 8 No. 4, pp. 490-510.

Schaper, S. (2016). Contemplating the usefulness of intellectual capital reporting: reasons behind the demise of IC disclosures in Denmark. Journal of Intellectual Capital, 17(1), 52-82.

Seal, W., \& Ye, L. (2014). The balanced scorecard and the construction of a management control discourse. Journal of Accounting \& Organizational Change, 10(4), 466-485. https://doi.org /10.1108/JAOC-10-2012-0098 